\title{
Does sarcopenia predict change in mobility after hip fracture? a multicenter observational study with one-year follow-
} up

Ole Martin Steihaug ${ }^{1}$ D, Clara Gram Gjesdal 2,3, Bård Bogen 1,4, Målfrid Holen Kristoffersen5, Gunhild Lien ${ }^{6}$, Karl Ove Hufthammer ${ }^{7}$ and Anette Hylen Ranhoff ${ }^{1,2,8^{*}}$

\begin{abstract}
Background: Patients with hip fracture frequently have sarcopenia and are at great risk of loss of mobility. We have investigated if sarcopenia predicts change in mobility after hip fracture.

Methods: This is a prospective, multicenter observational study with one-year follow-up. Patients with hip fracture who were community-living and capable of walking before the fracture were included at three hospitals in Norway (2011-2013). The primary outcome of the study was change in mobility, measured by the New Mobility Score (NMS). Sarcopenia was determined postoperatively by anthropometry, grip strength, and NMS.

Results: We included 282 participants and sarcopenia status was determined in 201, of whom 38\% (77/201) had sarcopenia, 66\% (128/194) had low muscle mass, 52\% (116/222) had low grip strength and 8\% (20/244) had low pre-fracture mobility (NMS $<5$ ). Sarcopenia did not predict change in mobility (effect 0.2 points; $95 \% \mathrm{Cl}-0.5$ to 0.9 , $P=0.6$ ), but it was associated with having lower mobility at one-year (NMS 5.8 (SD 2.3) vs. 6.8 (SD 2.2), $P=0.003$ ), becoming a resident of a nursing home (odds ratio $3.2,95 \% \mathrm{Cl} 0.9$ to $12.4, P=0.048$ ), and the combined endpoint of becoming a resident of a skilled nursing home or death (odds ratio $3.6,95 \% \mathrm{Cl} 1.2$ to $12.2, P=0.02$ ).
\end{abstract}

Conclusions: Sarcopenia did not predict change in mobility in the year after hip fracture.

Keywords: Activities of daily living, Hip fractures, Independent living, Mobility limitation, Skilled nursing facilities, Sarcopenia

\section{Background}

A hip fracture is associated with severe and persisting mobility impairment in more than half of patients [1]. For the last 30 years, a substantial effort has been made to understand the condition of sarcopenia, and several definitions have been proposed [2]. Sarcopenia has recently been recognized as an independent condition with its own ICD-10 code [3]. One of the most widely used definitions is by the European Working Group on Sarcopenia in Older Persons (EWGSOP): low muscle mass with low muscle strength or

\footnotetext{
* Correspondence: ahranhoff@yahoo.no

${ }^{1}$ Kavli Research Centre for Geriatrics and Dementia, Haraldsplass Deaconess Hospital, Bergen, Norway

${ }^{2}$ Department of Clinical Science, University of Bergen, Bergen, Norway Full list of author information is available at the end of the article
}

low physical performance [4]. Previous studies on sarcopenia in patients with hip fracture have been cross-sectional, single-center, have included few participants or have had short follow-ups [5-10]. The three components of EWGSOP sarcopenia have different associations with mobility after hip fracture. Physical performance and mobility are strong determinants of mobility after hip fracture [11, 12]. Muscle strength is a somewhat weaker predictor [13, 14], whereas the studies on muscle mass have been inconclusive [15]. Our primary hypothesis is that sarcopenia, determined by methods suitable for bed-side use, predicts change in mobility in the year after hip fracture and therefore that sarcopenia status is useful for determining prognosis and is a possible cause of mobility impairment. Further, we aim to describe the associations of sarcopenia and the individual 
components of sarcopenia (muscle mass, grip strength and mobility) and adverse clinical outcomes in the year after hip fracture: change in activities of daily living, reoperations for hip fracture, all-cause hospitalization, fractures, becoming a resident of a nursing home or death.

\section{Methods}

\section{Study design}

We conducted a prospective observational study of sarcopenia in patients with acute hip fracture with followup at three months and one year, conducted at three Norwegian hospitals in 2011-2013.

\section{Participants}

Participants were included while in hospital in the postoperative phase. Eligible participants were aged $\geq 65$ years, able to give informed consent as judged by experienced clinicians, were living in the community, and were ambulatory before the fracture. Patients who were unstable such as with delirium, acute respiratory failure or in severe pain were not eligible. Other exclusion criteria were dementia when it made informed consent impossible, remaining life expectancy of less than three months and bone disease other than osteoporosis or osteomalacia. We screened for participants by examining lists of patients admitted for hip fracture or staying on the hospital wards.

\section{Data collection}

Information was collected by the authors and study personnel by examination, chart review, routine blood tests and by interviews with patients and their caregivers from the first postoperative day and until discharge from hospital. Weight was measured with the scales on the hospital wards. We collected the American Society of Anesthesiologists (ASA) score, Charlson comorbidity index [16], Barthel activities of daily living (B-ADL) score [17], length of the acute care hospital stay, previous hip fracture and type of hip fracture. Follow-up was at 3 months at an outpatient clinic and at one year as a telephone interview with the patient or care-giver. Information on previous and subsequent hip fractures, and reoperations for the index hip fracture came from the Norwegian Hip Fracture Register [18]. This register started data collection in 2005 and has coverage on an estimated $90 \%$ of all hip fractures in Norway. The register has information on reoperations, with an estimated coverage of $65 \%$ of hip fractures treated with surgical pinning, $68 \%$ after hemiarthroplasty and $93 \%$ after total hip replacement [19]. Mortality data was supplied by the National Population Register, which is complete.

\section{Sarcopenia}

Participants were classified as sarcopenic if they had low muscle mass and either low grip strength or impaired mobility, as described by the EWGSOP [4]. Total body muscle mass was determined by anthropometry by the method of Heymsfield et al. using height, arm circumference and triceps skinfold [20]. Arm circumference was measured on the right arm using a non-elastic tape at the mid-point of the acromion and olecranon process, and triceps skinfold was measured on the posterior aspect of the same arm at the same level using a skinfold caliper (Harpenden, Baty International, Great Britain). Height was measured by a wall mounted stadiometer, or if the patients was unable to stand self-reported height was used. If the participant was unable to stand or report their height, the length from heel to crown was measured while lying in bed. In cases with missing value on height at baseline, height measured at follow-up was used. The values for total body muscle mass were transformed to appendicular lean mass (ALM) using model 1 described by Kim et al. [21]. The cut-points for low muscle mass were ALM $\leq 7.25 \mathrm{~kg} / \mathrm{m}^{2}$ for men and $\leq 5.67 \mathrm{~kg} / \mathrm{m}^{2}$ for women. We chose anthropometry for its ease of use at the bed-side in immobile hip fracture patients. Grip strength was measured with a Jamar Hydraulic Dynamometer (Sammons Preston, USA) while the patient was sitting in bed or on a chair with the elbow flexed, the wrist in the neutral position and with verbal encouragement. Grip strength was measured three times on each hand with short intervals between each attempt while the grip was repositioned. The single best value out of these six measurements was used. Low grip strength was $\leq 30 \mathrm{~kg}$ for men and $\leq 20 \mathrm{~kg}$ for women. Mobility in the two weeks before the hip fracture was determined by interview using the New Mobility Score (NMS). The NMS is scored 0-9 according to a person's ability to walk indoors, outdoors, or while shopping [22]. The cut-point for low mobility was chosen as $<5$, as this has been used to predict mortality after hip fracture [23]. We used a Danish version of the NMS with minimal modifications to Norwegian. Sarcopenia status was determined postoperatively and at follow-up.

\section{Outcome measures}

The primary outcome was change in mobility, calculated as NMS at one year minus the pre-fracture NMS. We believe that change in mobility is more relevant than mobility for identifying patients who are more likely to benefit from interventions. We determined mobility prefracture, at three months, and at one-year. All other analyses were considered exploratory. Other outcome variables at one year were NMS at one year, B-ADL at one year, change in $\mathrm{B}-\mathrm{ADL}$, new clinical fractures, new hip fractures, reoperation for hip fracture, all-cause hospitalizations, death, becoming a permanent resident of a skilled nursing home, and the combined endpoint of becoming a permanent resident of a nursing home or 
death. The combined endpoint was chosen because death and becoming a resident of a nursing home are competing risks. New clinical fracture was any symptomatic skeletal fracture reported by the patient.

\section{Statistical analysis}

We report descriptive data as means with standard deviations or as counts with percentages. To examine the predictive effect of sarcopenia status on changes in mobility and level of activity of daily living, we used linear regression analyses with NMS and B-ADL as response variables and sarcopenia status at baseline (sarcopenic vs. not sarcopenic) and age, sex and BMI as predictors. Age, sex and BMI were included in the models because they are established predictors of mobility after hip fracture [24] or sarcopenia [25]. The relationship with age and BMI was not assumed to be linear and was modelled using restricted cubic splines with 3 knots, placed at the 10\%, 50\% and 90\% quantiles. We assumed that a one-point change in NMS would be clinically significant. We used Fisher's exact test for the analysis of sarcopenia associated with new clinical fracture, new hip fracture, reoperations, all-cause hospitalization, becoming a resident of skilled nursing home, and the combined endpoint of nursing home or death. The association between the separate components of sarcopenia (muscle mass, grip strength and mobility) with change in mobility, change in $\mathrm{B}-\mathrm{ADL}$ and the combined endpoint of becoming a resident of a skilled nursing home or death was analysed using regression analysis. Muscle mass, grip strength and mobility were independent continuous variables, and were analyzed separately. Change in mobility and change in B-ADL were continuous, dependent variables and the combined endpoint of becoming resident of a nursing home or death was a dichotomous dependent variable.

For the regression analyses, we used multiple imputation (500 imputations), based on predictive mean matching, using the 'aregImpute()' function in the 'rms' $\mathrm{R}$ package [26]. The variables used in the imputation models were the ones included in the regression models, variables highly correlated with these variables and variables expected to explain the missing data mechanism: NMS at baseline, follow-up, and at one year, and change in NMS from baseline to one year, B-ADL before the hip fracture and change in B-ADL from pre-fracture until one year, sarcopenia status at baseline, BMI at baseline, ASA score during hip fracture surgery, previous hip fracture, serum albumin when in hospital, grip strength at follow-up, sex, clinical fractures and hip fractures in the year after admission, becoming a resident of a skilled nursing home, or dying in the following year. All continuous predictors were modelled linearly in the imputation model. The imputation analyses were done in R 3.3.0 [27] and the rest of the analyses were done in Stata 14 (Stata Corp., USA). Pvalues $\leq 0.05$ were considered significant.

\section{Results}

All patients in hospital with confirmed hip fracture were considered for inclusion if the research staffs at the different hospitals were present. Some patients were unable to participate because they were discharged before the two-day consent process was completed. There was no systematic recording of the patients who were screened, but not included. Figure 1 describes the progress of participants through hip fracture, inclusion in the study and follow-up. During the period of inclusion 1592 patients had surgery for hip fracture and 282 patients were included in the study.

Mean age was 79.4 (SD 8.2) years and 76\% were female. Mean BMI was 24.1 (SD 4.3) $\mathrm{kg} / \mathrm{m}^{2}$, with a wide range 13.0 to $44.7 \mathrm{~kg} / \mathrm{m}^{2}$. See Table 1 for baseline demographics. One patient died during the hospital stay. Participants who had missing data on sarcopenia status during hospitalization had lower pre-fracture NMS and pre-fracture B-ADL and were more likely to become a permanent resident of a skilled nursing home. For 69 participants, height was not assessed during the hospital stay, and for 52 of these, height determined at follow-up was used.

\section{Sarcopenia}

Sarcopenia status during hospitalization for hip fracture was determined in 201 participants, and 39\% (77/201) had sarcopenia. Low muscle mass was present in $66 \%$ $(128 / 194)$ of the participants, low grip strength in $52 \%$ $(116 / 222)$, and $8 \%$ had low pre-fracture mobility (19/ 243). One participant did not have muscle mass determined but had grip strength and NMS above the cutpoints and was considered not-sarcopenic. Figure 2 . Participants with sarcopenia were older, had lower BMI, greater ASA score at operation, greater prevalence of previous hip fracture and pulmonary disease and lower B-ADL before the fracture. Grip strength and ALM were assessed at a median of 4 days after surgery (interquartile range 3 to 6 days) (Fig. 2).

\section{Outcomes after one year}

Sarcopenia was not associated with change in mobility at one year in unadjusted or adjusted analyses (e.g., the change in NMS was an additional 0.2 in sarcopenic patients compared to non-sarcopenic patients, 95\% CI: 0.5 to $0.9, P=0.6$ ); see Table 2 for outcomes at one-year. Sarcopenia status at hospitalization did not predict change in mobility from pre-fracture to 3 months, or from 3 months to one-year. Results were not affected by imputation of missing values. Mobility was reduced in $54 \%$ of participants one year after hip fracture, with a mean NMS of 6.4 (SD 2.2). See Fig. 3 for NMS by sarcopenia status during the year after hip fracture. Figure 4 describes the relationship between specific scores on the NMS pre-fracture and at one-year. Participants with sarcopenia had lower mobility at one-year, NMS 5.8 (SD 


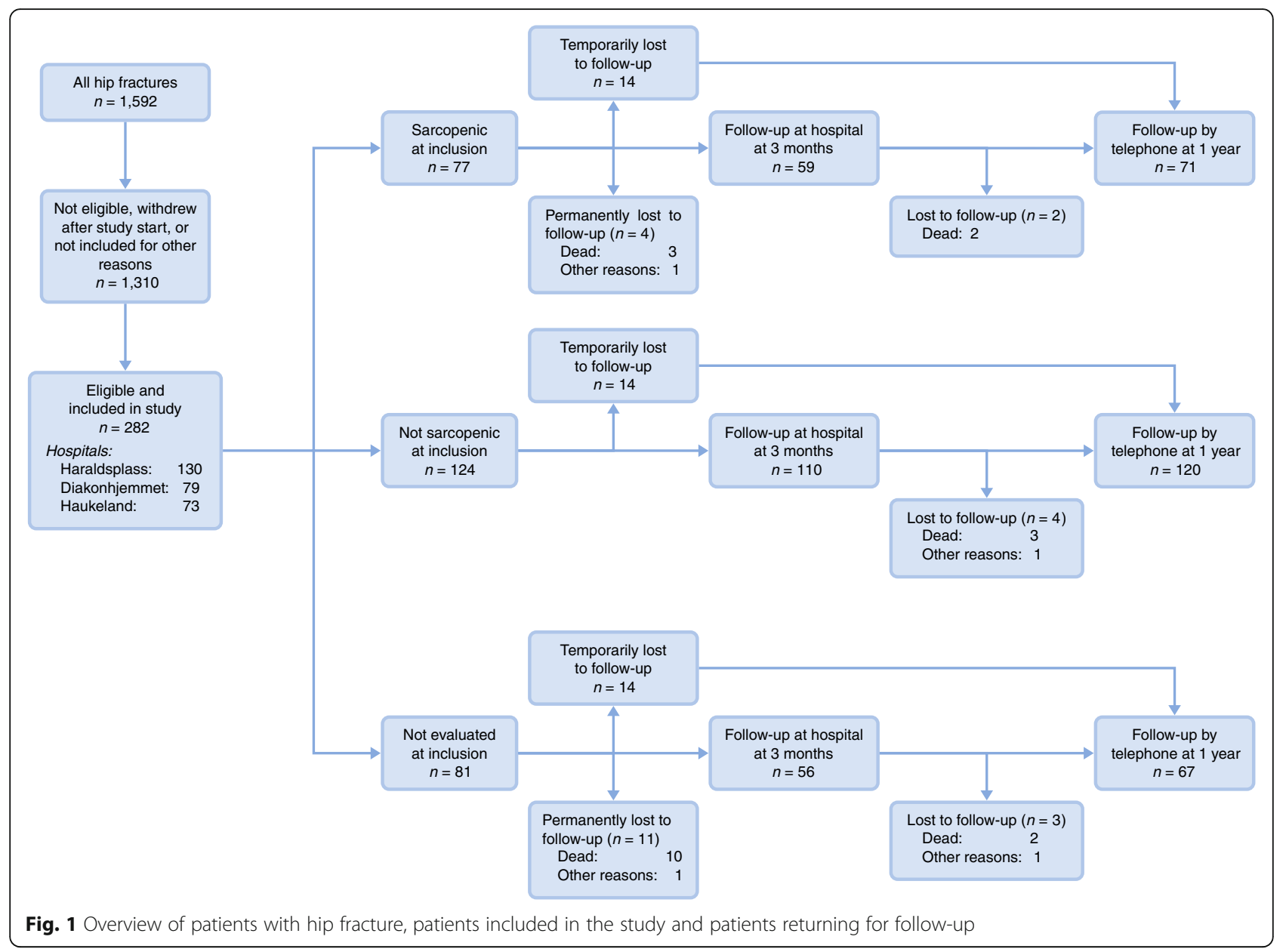

2.3 ) vs. 6.8 (SD 2.2), $P=0.003$, and greater impairment in B-ADL, 16.8 (SD 4.4) vs. 18.6 (SD 2.8), $P=0.001$, compared to patients without sarcopenia. Sarcopenia was associated with becoming a permanent resident of a skilled nursing home (OR 3.2, 95\% CI: 0.9 to $12.4, P=$ 0.048 ) and the combined endpoint of becoming a resident of a skilled nursing home or death (OR 3.6, 95\% CI: 1.2 to $12.3, P=0.02$ ).

\section{Muscle mass, grip strength and mobility}

Muscle mass or grip strength was not associated with any outcome in adjusted analysis Table 3. In unadjusted analysis, grip strength and NMS were associated with a reduced risk of becoming a resident of a nursing home or death. The NMS was positively associated with change in B-ADL in adjusted analysis (estimate 0.2 per point, $95 \%$ CI 0.0 to $0.4, P=0.03$ ).

\section{Discussion}

The aim of this study was to investigate if sarcopenia predicted change in mobility after hip fracture. We found that sarcopenia status did not predict change in mobility in unadjusted analysis, which indicates that sarcopenia is not useful in determining prognosis. Further, sarcopenia did not predict change in mobility in analysis adjusted for age, sex and BMI, which indicates that sarcopenia status is not likely to be causally related to developing reduced mobility. We used multiple imputation to reduce the loss of information associated with missing values. This approach is considered inferior to having all the data, but preferable to performing analysis on complete data. One assumption of multiple imputation is that missing values can be estimated by the remaining information in the dataset. The results of our analysis were similar when analyzing complete cases and when analyzing datasets with imputed values, indicating that the results of our analysis are valid even if this assumption was erroneous.

Change in mobility was not associated with sarcopenia and this was consistent across all the investigated time periods, from baseline to three months, from baseline to one year and from three months to one year. Mobility from before the hip fracture until one year is characterized by an initial loss of mobility and a subsequent partial recovery. Sarcopenia is not associated with either the loss of mobility or the recovery, which further supports 
Table 1 Baseline characteristics of participants by sarcopenia status

\begin{tabular}{|c|c|c|c|c|c|c|c|}
\hline \multirow[b]{2}{*}{ Age, years (SD) } & \multicolumn{3}{|c|}{ Not sarcopenic } & \multicolumn{3}{|c|}{ Sarcopenic } & \multirow{2}{*}{$\frac{P \text {-value }}{<0.0001}$} \\
\hline & 77.1 & $(7.8)$ & $n=124$ & 81.8 & $(7.6)$ & $n=77$ & \\
\hline Female, n (\%) & 95 & (77) & $n=124$ & 56 & (72) & $n=77$ & 0.5 \\
\hline $\begin{array}{l}\text { Barthel ADL } \\
\text { pre-fracture (SD) }\end{array}$ & 19.5 & $(1.1)$ & $n=85$ & 18.7 & $(1.9)$ & $n=60$ & 0.006 \\
\hline Type of hip fracture & & & & & & & 0.6 \\
\hline $\begin{array}{l}\text { Neck of femur, } \\
\text { not displaced, } \\
\text { n (\%) }\end{array}$ & 29 & (24) & $n=123$ & 14 & (18) & $n=77$ & \\
\hline $\begin{array}{l}\text { Neck of femur, } \\
\text { displaced, n (\%) }\end{array}$ & 46 & (37) & $n=123$ & 31 & (40) & $n=77$ & \\
\hline $\begin{array}{l}\text { Trochanteric, } \\
\text { n (\%) }\end{array}$ & 48 & (39) & $n=123$ & 32 & $(42)$ & $n=77$ & \\
\hline ASA score (SD) & 2.3 & $(0.6)$ & $n=124$ & 2.7 & $(0.6)$ & $n=77$ & $<0.001$ \\
\hline $\begin{array}{l}\text { Previous hip } \\
\text { fracture, n (\%) }\end{array}$ & 5 & (4) & $n=124$ & 9 & $(12)$ & $n=77$ & 0.039 \\
\hline Charlson score (SD) & 0.9 & (1.3) & $n=124$ & 1.1 & (1.3) & $n=77$ & 0.15 \\
\hline Heart failure, n (\%) & 7 & (6) & $n=124$ & 6 & (8) & $n=77$ & 0.5 \\
\hline $\begin{array}{l}\text { Previous myocardial } \\
\text { infarction, } \mathrm{n}(\%)\end{array}$ & 14 & (11) & $n=124$ & 9 & $(12)$ & $n=77$ & 0.9 \\
\hline $\begin{array}{l}\text { Cerebrovascular } \\
\text { disease, n (\%) }\end{array}$ & 13 & (10) & $n=124$ & 8 & $(10)$ & $n=77$ & 0.98 \\
\hline $\begin{array}{l}\text { Diabetes } \\
\text { mellitus, n (\%) }\end{array}$ & 9 & (7) & $n=124$ & 10 & (13) & $n=77$ & 0.2 \\
\hline $\begin{array}{l}\text { Any solid } \\
\text { tumor, n (\%) }\end{array}$ & 7 & (6) & $n=124$ & 8 & (10) & $n=77$ & 0.2 \\
\hline $\begin{array}{l}\text { Pulmonary } \\
\text { disease, n (\%) }\end{array}$ & 15 & (12) & $n=124$ & 18 & (23) & $n=77$ & 0.036 \\
\hline $\begin{array}{l}\text { Length of hospital } \\
\text { stay, days (SD) }\end{array}$ & 6.8 & $(2.7)$ & $n=124$ & 9.6 & $(6.7)$ & $n=77$ & $<0.001$ \\
\hline \multicolumn{8}{|l|}{ Body composition } \\
\hline $\mathrm{BMI}, \mathrm{kg} / \mathrm{m}^{2}(\mathrm{SD})$ & 25.6 & $(4.2)$ & $n=107$ & 22.1 & (3.7) & $n=70$ & $<0.001$ \\
\hline $\begin{array}{l}\text { ALM/height }{ }^{2} \\
\mathrm{~kg} / \mathrm{m}^{2} \text { (SD) }\end{array}$ & 6.3 & (1.5) & $n=111$ & 4.4 & $(1.0)$ & $n=77$ & $<0.001$ \\
\hline Women & 6.1 & (1.3) & $n=86$ & 4.3 & $(0.8)$ & $n=56$ & $<0.001$ \\
\hline Men & 7.0 & $(1.7)$ & $n=25$ & 4.8 & $(1.2)$ & $n=21$ & $<0.001$ \\
\hline \multicolumn{8}{|l|}{ Grip strength } \\
\hline $\begin{array}{l}\text { Grip strength, } \\
\text { kg (SD) }\end{array}$ & 27.0 & $(10.3)$ & $n=123$ & 16.5 & $(6.4)$ & $n=77$ & $<0.001$ \\
\hline Women & 22.9 & $(6.9)$ & $n=94$ & 14.3 & $(5.0)$ & $n=56$ & $<0.001$ \\
\hline Men & 40.1 & $(8.3)$ & $n=29$ & 22.3 & $(5.9)$ & $n=21$ & $<0.001$ \\
\hline \multicolumn{8}{|l|}{ Mobility } \\
\hline $\begin{array}{l}\text { New Mobility } \\
\text { Score (SD) }\end{array}$ & 8.0 & (1.5) & $n=123$ & 7.1 & (2.0) & $n=74$ & $<0.001$ \\
\hline Women & 8.0 & (1.6) & $n=94$ & 7.1 & (2.0) & $n=55$ & 0.008 \\
\hline Men & 8.2 & (1.4) & $n=29$ & 6.8 & $(2.2)$ & $n=19$ & 0.017 \\
\hline
\end{tabular}

Baseline characteristics by sarcopenia status (means with standard deviations and counts with percentages). $P$-values for comparison of groups are by the Mann-Whitney-Wilcoxon test, except for type of fracture which is by chi-squared test. Trochanteric fractures include basocervical femoral neck fractures and subtrochanteric fractures. Previous hip fracture indicates a previous hip fracture, either left or right hip. ALM: Appendicular lean mass, ADL: Activities of daily living that sarcopenia is not related to change in mobility. In contrast to change in mobility, being sarcopenic was associated with having lower mobility pre-fracture, at three months and at one year, compared to not being sarcopenic. This is expected, since low mobility is one criteria for sarcopenia. As seen in Fig. 4, pre-fracture mobility is a determinant of mobility at three months and one year. Savino et al. found that grip strength measured in hospital predicted recovery of walking ability in patients with hip fracture [13]. In contrast, our findings indicate that neither muscle mass nor grip strength, when analysed as continuous variables, were associated with change in mobility. This indicates that the choice of cutpoints for low muscle mass or low grip strength would not have changed our results. We found an association between mobility pre-fracture and change in activities in daily living, but this was an exploratory analysis and the effect size was small.

Sarcopenia was associated with an increased probability of becoming a resident of a skilled nursing home (OR 3.2, $95 \%$ CI 0.9 to $12.4, P=0.048$ ) and the combined endpoint of becoming a resident of a nursing home or death (OR $3.6,95 \%$ CI 1.2 to $12.3, P=0.02$ ). This is a clinically relevant finding but must be interpreted with caution, as it was an exploratory outcome and we were not able to correct for age, sex or BMI because of the low number of outcomes. Among the participants who had sarcopenia status determined, 6 participants died or became permanent residents of a nursing home among the not sarcopenic and 12 participants among those who were sarcopenic. The NMS was chosen as our measure of physical performance because we assumed that many participants would be unable to walk at inclusion. The NMS is extensively studied as a predictor of mobility, morbidity, mortality and becoming a resident of a nursing home [28-31]. We found a ceiling effect with the NMS, with $54 \%$ of participants scoring the maximum 9 before the fracture and 30\% at one-year. Possibly because participants with a pre-fracture NMS of 0 or 1 were not eligible for inclusion. Patients found the NMS easy to understand and scoring was straightforward. Surprisingly, we found that $8 \%$ of patients had better mobility at oneyear compared to pre-fracture. For some of the patients this was due to illness that started before the fracture, and their improvement in mobility after hip fracture was due to resolution of their illness, rather than successful rehabilitation. Use of rehabilitation services improves mobility after hip fracture [32, 33]. We did not record what rehabilitation services the participants received, and it is possible that rehabilitation could mediate the effect between sarcopenia and change in mobility.

The participants in our study were slightly younger (79.4 vs. 80.0 years) and had a lower mean ASA score (2.5 vs. 2.7) indicating better health compared to patients in the Norwegian Hip Fracture Register. We did not include 


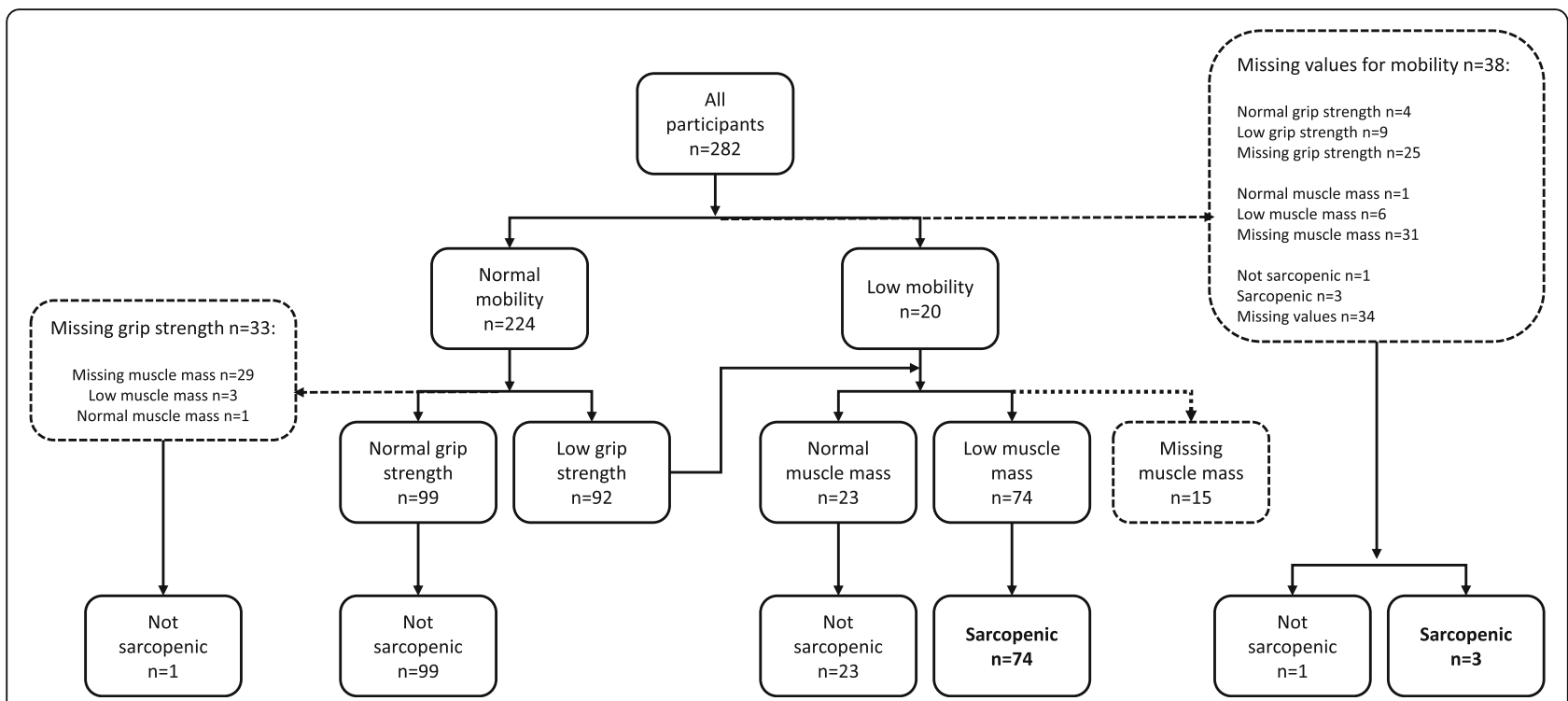

Fig. 2 What participants were assessed for muscle mass, grip strength, mobility and sarcopenia

patients from skilled nursing homes or with severe cognitive impairment, and our results are not generalizable to those populations.

Anthropometry is considered a less valid method for determining muscle mass compared to dual-energy $\mathrm{X}$ ray absorptiometry (DXA) or computed tomography scan [34]. The EWGSOP recommends not using anthropometry to determine muscle mass in research but allows for it in clinical practice [4]. We have previously investigated how anthropometry compares to DXA in identifying low muscle mass and found an area under the curve of 0.64 (95\% CI $0.54-0.75)$ in women and 0.72
(95\% CI 0.56-0.87) in men [35]. Using anthropometry to identify low muscle mass instead of DXA can lead to misclassification of muscle mass status and hence sarcopenia status. By using anthropometry to determine sarcopenia status we reduced our ability to detect an effect of sarcopenia on outcomes. We used anthropometry in our study because it is in common use [36], inexpensive, and more easily performed on patients with reduced mobility and acute illness, compared to DXA [37]. Some consider objectively measured physical performance superior to self-reported mobility, such as the NMS, but when the two types of measurement are compared in

Table 2 Outcomes after one year by sarcopenia status

\begin{tabular}{|c|c|c|c|c|c|c|c|c|c|c|c|c|}
\hline & \multicolumn{6}{|c|}{ Marginal values } & \multicolumn{6}{|c|}{ Regression (sarcopenic - not sarcopenic) } \\
\hline & \multicolumn{3}{|c|}{ Not sarcopenic } & \multicolumn{3}{|c|}{ Sarcopenic } & \multicolumn{3}{|c|}{ Unadjusted } & \multicolumn{3}{|l|}{ Adjusted } \\
\hline & Mean & (SD) & No. & Mean & (SD) & No. & Estimate & $95 \% \mathrm{Cl}$ & $P$ & Estimate & $95 \% \mathrm{Cl}$ & $P$ \\
\hline Change NMS & -1.2 & $(1.8)$ & $n=117$ & -1.3 & (1.9) & $n=67$ & 0.0 & -0.6 to 0.6 & 0.9 & 0.2 & -0.5 to 0.9 & 0.6 \\
\hline \multirow[t]{2}{*}{ Change B-ADL } & -0.8 & $(2.4)$ & $n=76$ & -2.2 & $(3.9)$ & $n=52$ & -0.4 & -1.2 to 0.3 & 0.3 & -0.3 & -1.1 to 0.6 & 0.6 \\
\hline & & & & \multicolumn{3}{|c|}{ Not Sarcopenic } & \multicolumn{3}{|c|}{ Sarcopenic } & OR & $95 \% \mathrm{Cl}$ & $P$ \\
\hline \multicolumn{4}{|l|}{ Fracture, $\mathrm{n}(\%) \mathrm{N}$} & 7 & (6) & $n=120$ & 8 & $(11)$ & $n=71$ & 2.0 & (0.6 to 7.0$)$ & 0.3 \\
\hline \multicolumn{4}{|c|}{ Hip fractures, n (\%) N } & 3 & (2) & $n=124$ & 3 & (4) & $n=77$ & 1.6 & (0.2 to 12.5$)$ & 0.7 \\
\hline \multicolumn{4}{|c|}{ Reoperations, n (\%) N } & 7 & (6) & $n=124$ & 1 & $(1)$ & $n=77$ & 0.2 & (0.0 to 1.8$)$ & 0.2 \\
\hline \multicolumn{4}{|c|}{ Hospitalization, n (\%) N } & 41 & (33) & $n=123$ & 24 & (33) & $n=73$ & 1.0 & (0.5 to 1.9$)$ & 1.0 \\
\hline \multicolumn{4}{|c|}{ Nursing home, n (\%) N } & 5 & (4) & $n=124$ & 9 & (12) & $n=77$ & 3.2 & (0.9 to 12.4$)$ & 0.048 \\
\hline \multicolumn{4}{|l|}{ Death, $n(\%) N$} & 3 & (2) & $n=124$ & 5 & (6) & $n=77$ & 2.8 & (0.5 to 18.5$)$ & 0.3 \\
\hline \multicolumn{4}{|c|}{ Death or nursing home, $\mathrm{n}(\%) \mathrm{N}$} & 6 & (5) & $n=124$ & 12 & $(16)$ & $n=77$ & 3.6 & (1.2 to 12.3$)$ & 0.02 \\
\hline
\end{tabular}

Outcomes after one year by sarcopenia status (sarcopenic - not sarcopenic). Regression analysis for change in mobility and Barthel ADL from pre-fracture until one year adjusted for age, sex and BMI with imputation of missing values. ADL: Barthel Activities of daily living. Analysis for fracture, hip fracture, reoperations, all-cause hospitalization, nursing home, death or nursing home or death by two-sided Fisher's exact test using available cases. NMS: New mobility score. B-ADL: Barthel activities of daily living. OR: Odds ratio 


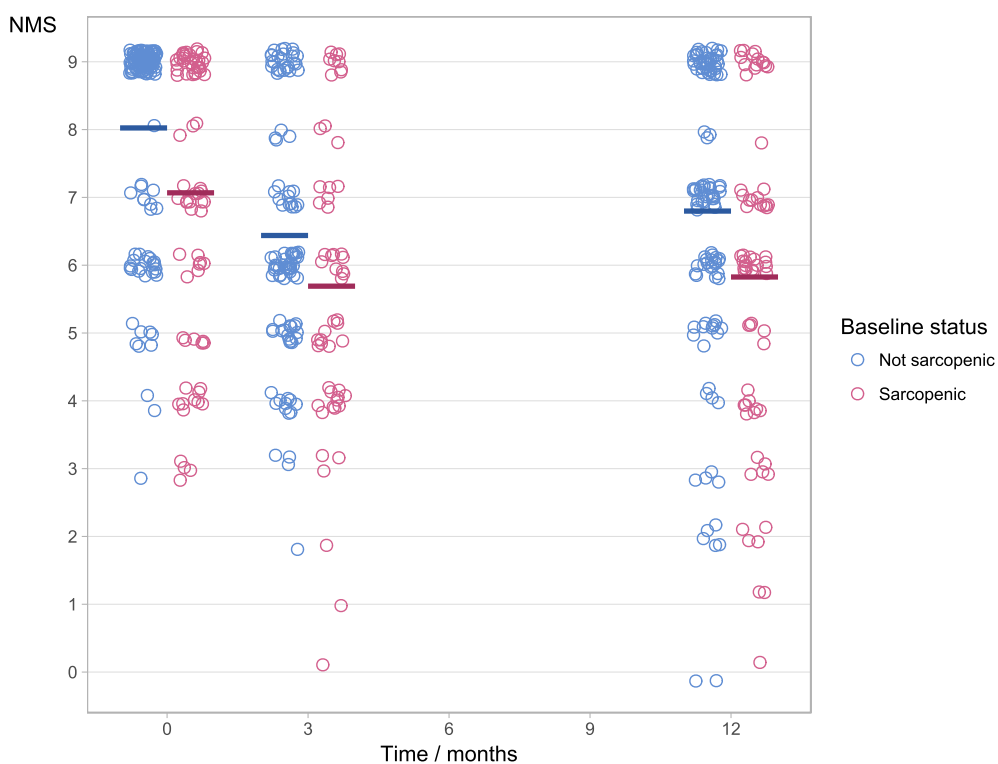

Fig. 3 New Mobility Score (NMS) during hospitalization, at three months, and at one year, stratified by sarcopenia status during hospitalization. The horizontal lines show mean NMS scores

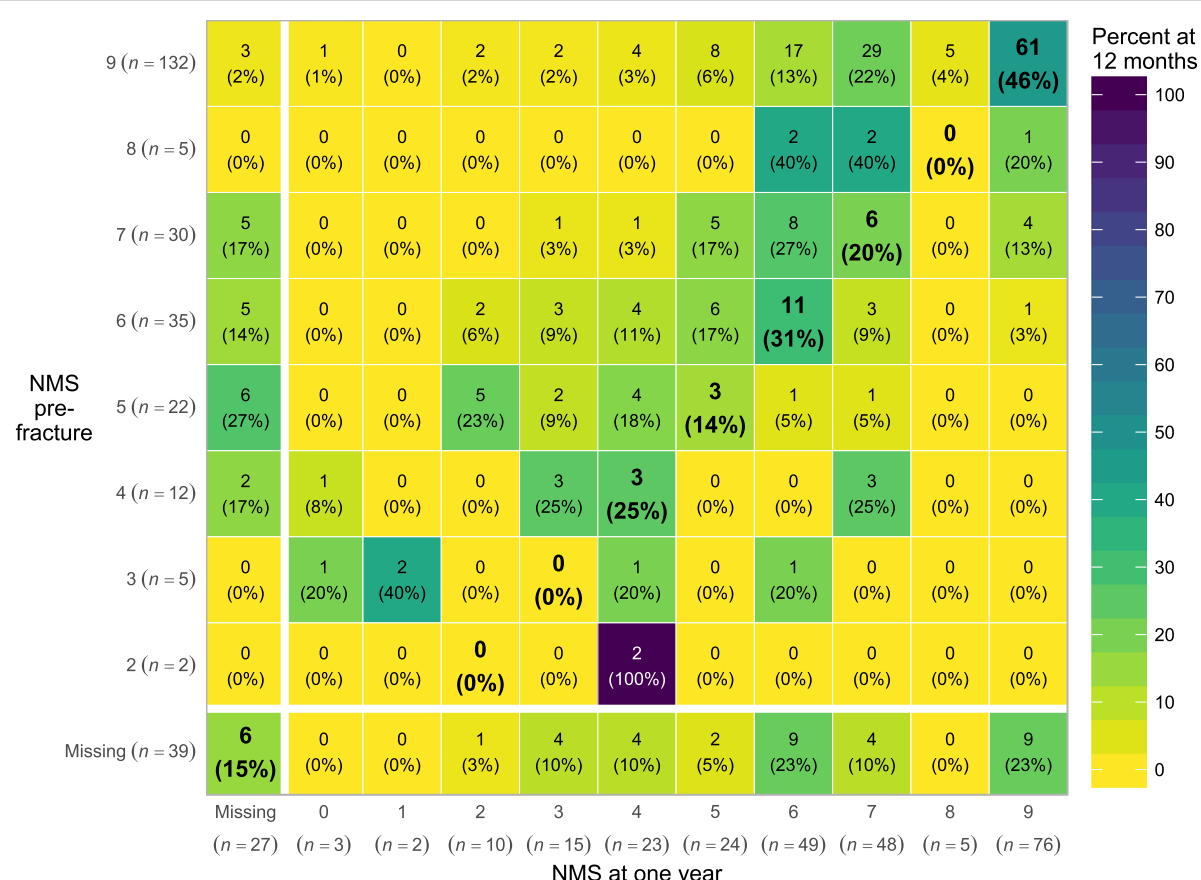

Fig. 4 New Mobility Score (NMS) pre-fracture and at one-year follow-up. The first number in each cell is the number of patients with the given combination of NMS scores. For each row, the percentage values and the cell shadings show the distribution of NMS at follow-up for a given NMS score at baseline. No patients had a NMS of 1 at baseline, and patients with a NMS score of 0 was excluded from the study. Patients with the same NMS score at baseline and follow-up are shown in boldface, and any cell to the right of this diagonal indicates an improvement in the NMS 
Table 3 Outcomes after one year predicted by muscle mass, grip strength or mobility

\begin{tabular}{|c|c|c|c|c|c|c|c|c|}
\hline & $\begin{array}{l}\text { Unas } \\
\beta(9:\end{array}$ & $\begin{array}{l}\text { ed } \\
\text { onfidence inte }\end{array}$ & & & $\begin{array}{l}\text { Adjus } \\
\beta(95 \\
\end{array}$ & nfidence inter & & \\
\hline Change in New Mobility Score & ne ye & & & & & & & \\
\hline ALM/height ${ }^{2}, \mathrm{~kg} / \mathrm{m}^{2}$ & 0.0 & $(-0.1$ to 0.2$)$ & $p=0.7$ & $n=175$ & 0.2 & $(-0.1$ to 0.4$)$ & $p=0.2$ & $n=155$ \\
\hline Grip strength, kg & 0.0 & $(-0.0$ to 0.0$)$ & $p=0.7$ & $n=193$ & -0.0 & $(-0.0$ to 0.0$)$ & $p=0.7$ & $n=169$ \\
\hline Change in Barthel activities of & livin & one year & & & & & & \\
\hline ALM/height ${ }^{2}, \mathrm{~kg} / \mathrm{m}^{2}$ & 0.0 & $(-0.2$ to 0.3$)$ & $p=0.8$ & $n=121$ & 0.1 & $(-0.2$ to 0.4$)$ & $p=0.4$ & $n=115$ \\
\hline Grip strength, kg & 0.0 & $(-0.0$ to 0.1$)$ & $p=0.07$ & $n=137$ & 0.0 & (0.0 to 0.1$)$ & $p=0.1$ & $n=128$ \\
\hline New Mobility Score, point & 0.2 & (0.0 to 0.4$)$ & $p=0.03$ & $n=148$ & 0.2 & (0.0 to 0.4$)$ & $p=0.03$ & $n=130$ \\
\hline Death or nursing home at one & & & & & & & & \\
\hline ALM/height ${ }^{2}, \mathrm{~kg} / \mathrm{m}^{2}$ & 0.8 & (0.6 to 1.2$)$ & $p=0.3$ & $n=194$ & 1.0 & (0.6 to 1.7$)$ & $p=1.0$ & $n=170$ \\
\hline Grip strength, kg & 0.9 & (0.9 to 1.0$)$ & $p=0.002$ & $n=222$ & 0.9 & (0.9 to 1.0$)$ & $p=0.1$ & $n=186$ \\
\hline New Mobility Score, point & 0.7 & (0.6 to 0.9$)$ & $p<0.001$ & $n=243$ & 0.8 & (0.6 to 1.0 ) & $p=0.06$ & $n=194$ \\
\hline
\end{tabular}

Outcomes after one year by muscle mass, grip strength or mobility. Analysis of change in mobility and Barthel activities of daily living by regression and with imputation of missing values. ALM/height ${ }^{2}$, grip strength and New Mobility Score are continuous, independent variables. Change in New Mobility Score and Barthel activities of daily living are continuous dependent variables. $n$ : number of cases without missing values. OR: Odds ratio, ALM: Appendicular lean mass. Adjusted analysis with age, sex and BMI as covariates

hip fracture patients they have been found to be equally predictive of outcomes [38]. Future research on sarcopenia in hip fracture patients could explore other methods for determining sarcopenia, such as computed tomography to directly measure intramuscular adipose tissue [34] or using objective measures of physical performance such as the Short Physical Performance Battery [39]. A randomized controlled study of an intervention targeting sarcopenia status to improve mobility after hip fracture would provide additional insight on the causal relation between sarcopenia and mobility.

The included patients were a minority of all patients operated on for hip fracture during the period of inclusion. We included postoperative patients who were frequently bed-bound, receiving opiates for pain relief, with indwelling urinary catheters and while receiving intravenous fluid therapy. We believe there were three main reasons for the low recruitment rate: patients did not fulfill the inclusion criteria, patients were discharged before the consent process could be completed, and participants declined to participate because it was too much of a burden. For the patients who did consent to participate we found that determining sarcopenia by anthropometry, grip strength and the NMS was feasible. The greatest difficulty was in determining the height of the participants.

\section{Conclusion}

Sarcopenia status determined in postoperative hip fracture patients by anthropometry, grip strength and selfreported mobility did not predict change in mobility in the year after hip fracture. Sarcopenia was associated with having lower mobility at one year and a greater risk of becoming a resident of a nursing home or death.

\section{Abbreviations}

ALM: Appendicular lean mass; ASA: ASA Physical Status Classification System score.; B-ADL: Barthel activities of daily living; BMl: Body mass index; $\mathrm{Cl}$ : Confidence interval; DXA: Dual-energy X-ray absorptiometry; EWGSOP: European Working Group on Sarcopenia in Older Persons; NMS: New mobility score; OR: Odds ratio; SD: Standard deviation

\section{Acknowledgements}

We thank research nurses Britt Pedersen, Cathrine Sandnes, Mette Irene Martinsen, Christine Ekrheim and Elin Engh, and physical therapist Sylvia Sunde for assistance with data collection. We are grateful to associate professor Mala Naik for proof-reading the manuscript.

\section{Funding}

The Western Norway Regional Health Authority, Stavanger, Norway and Haraldsplass Deaconess Hospital, Bergen, Norway supported the study. The financial sponsors had no role in the design and execution of the study, analysis and interpretation of data, or writing of the manuscript.

\section{Availability of data and materials}

The datasets generated and analyzed during the current study are available from the corresponding author on reasonable request.

\section{Authors' contributions}

OMS, AHR, BB and CGG designed the study and wrote the study protocol. All authors have contributed to the manuscript, agree on submitting it for publication, and vouch for the integrity of the data and analysis. OMS and MHK have been responsible for including patients and data collection. OMS performed all data analyses except the regression analyses that used multiple imputation. AHR has been the project leader. $\mathrm{KOH}$ performed the regression analyses that used multiple imputation and prepared all the figures. All authors read and approved the final manuscript.

\section{Ethics approval and consent to participate}

The study was approved by the research committees at the participating hospitals (Haraldsplass Deaconess Hospital and Haukeland University Hospital, Bergen, and Diakonhjemmet Hospital, Oslo, Norway), the Regional Committee on Medical and Health Research Ethics (case 2011/1322/REK sør-øst B) and was conducted according to the principles of the Declaration of Helsinki. Participation was by written informed consent with participants receiving oral and written information on the first day and signed the consent form on a subsequent day. 


\section{Competing interests}

The authors declare that they have no competing interests.

\section{Publisher's Note}

Springer Nature remains neutral with regard to jurisdictional claims in published maps and institutional affiliations.

\section{Author details}

${ }^{1}$ Kavli Research Centre for Geriatrics and Dementia, Haraldsplass Deaconess Hospital, Bergen, Norway. ${ }^{2}$ Department of Clinical Science, University of Bergen, Bergen, Norway. ${ }^{3}$ Department of Rheumatology, Haukeland University Hospital, Bergen, Norway. ${ }^{4}$ Western Norway University of Applied Sciences, Bergen, Norway. ${ }^{5}$ Department of Orthopedics, Haukeland University Hospital, Bergen, Norway. ${ }^{6}$ Department of Rheumatology, Diakonhjemmet Hospital, Oslo, Norway. ${ }^{7}$ Centre for Clinical Research, Haukeland University Hospital, Bergen, Norway. ${ }^{8}$ Department of Clinical Science, the Faculty of Medicine and Dentistry, University of Bergen, Postbox 7804, n-5020 Bergen, Norway.

\section{Received: 8 May 2017 Accepted: 27 February 2018} Published online: 05 March 2018

\section{References}

1. Dyer SM, Crotty M, Fairhall N, Magaziner J, Beaupre LA, Cameron ID, Sherrington C. Fragility fracture network rehabilitation research special interest G: a critical review of the long-term disability outcomes following hip fracture. BMC Geriatr. 2016;16:158.

2. Dawson-Hughes $B$, Bischoff-Ferrari $\mathrm{H}$. Considerations concerning the definition of sarcopenia. Osteoporos Int. 2016;27(11):3139-44.

3. Dodds RM, Sayer AA. Sarcopenia, frailty and mortality: the evidence is growing. Age Ageing. 2016:45(5):570-1.

4. Cruz-Jentoft AJ, Baeyens JP, Bauer JM, Boirie Y, Cederholm T, Landi F, Martin FC, Michel JP, Rolland Y, Schneider SM, et al. Sarcopenia: European consensus on definition and diagnosis: report of the European working group on sarcopenia in older people. Age Ageing. 2010;39(4):412-23.

5. Perez-Zepeda MU, Sgaravatti A, Dent E. Sarcopenia and post-hospital outcomes in older adults: a longitudinal study. Arch Gerontol Geriatr. 2017; 69:105-9.

6. Ho AW, Lee MM, Chan EW, Ng HM, Lee CW, Ng WS, Wong SH. Prevalence of pre-sarcopenia and sarcopenia in Hong Kong Chinese geriatric patients with hip fracture and its correlation with different factors. Hong Kong Med J. 2016:22(1):23-9

7. Gonzalez-Montalvo Jl, Alarcon T, Gotor P, Queipo R, Velasco R, Hoyos R, Pardo A, Otero A. Prevalence of sarcopenia in acute hip fracture patients and its influence on short-term clinical outcome. Geriatr Gerontol Int. 2016; 16(9):1021-7.

8. Di Monaco M, Castiglioni C, De Toma E, Gardin L, Giordano S, Di Monaco R, Tappero R. Presarcopenia and sarcopenia in hip-fracture women: prevalence and association with ability to function in activities of daily living. Aging Clin Exp Res. 2015:27(4):465-72

9. Malafarina V, Uriz-Otano F, Malafarina C, Martinez JA, Zulet MA. Effectiveness of nutritional supplementation on sarcopenia and recovery in hip fracture patients. A multi-Centre randomized trial. Maturitas. 2017:101:42-50.

10. Landi F, Calvani R, Ortolani E, Salini S, Martone AM, Santoro L, Santoliquido A, Sisto A, Picca A, Marzetti E. The association between sarcopenia and functional outcomes among older patients with hip fracture undergoing inhospital rehabilitation. Osteoporos Int. 2017:1-8.

11. Kristensen MT. Factors affecting functional prognosis of patients with hip fracture. Eur J Phys Rehabil Med. 2011:47(2):257-64.

12. Pajulammi HM, Pihlajamaki HK, Luukkaala TH, Nuotio MS. Pre- and perioperative predictors of changes in mobility and living arrangements after hip fracture-a population-based study. Arch Gerontol Geriatr. 2015; 61(2):182-9.

13. Savino E, Martini E, Lauretani F, Pioli G, Zagatti AM, Frondini C, Pellicciotti F, Giordano A, Ferrari A, Nardelli A, et al. Handgrip strength predicts persistent walking recovery after hip fracture surgery. Am J Med. 2013;126(12):106875. e1061

14. Visser M, Harris TB, Fox KM, Hawkes W, Hebel JR, Yahiro JY, Michael R, Zimmerman SI, Magaziner J. Change in muscle mass and muscle strength after a hip fracture: relationship to mobility recovery. J Gerontol A Biol Sci Med Sci. 2000;55(8):M434-40.
15. Wehren LE, Hawkes WG, Hebel JR, Orwig DL, Magaziner J. Bone mineral density, soft tissue body composition, strength, and functioning after hip fracture. J Gerontol A Biol Sci Med Sci. 2005;60(1):80-4.

16. Charlson ME, Pompei $\mathrm{P}$, Ales KL, MacKenzie CR. A new method of classifying prognostic comorbidity in longitudinal studies: development and validation. J Chronic Dis. 1987:40(5):373-83.

17. Mahoney FI, Barthel DW. Functional evaluation: the Barthel index. Md State Med J. 1965;14:61-5.

18. Gjertsen JE, Dybvik E, Furnes O, Fevang JM, Havelin LI, Matre K, Engesaeter LB. Improved outcome after hip fracture surgery in Norway. Acta Orthop. 2017:88(5):505-11.

19. Havelin L.I. FO, Engesæter, L. B.; Fenstad, A. M.; Bartz-Johannessen, C; Dybvik, E; Fjeldsgaard, K.; Gundersen, T.. Norwegian National Advisory Unit on Arthroplasty and Hip Fractures. Annual Report. 2016. In. Bergen, Norway: Helse Bergen HF, Ortopedisk klinikk, Haukeland universitetssjukehus; 2016: 305.

20. Heymsfield SB, McManus C, Smith J, Stevens V, Nixon DW. Anthropometric measurement of muscle mass: revised equations for calculating bone-free arm muscle area. Am J Clin Nutr. 1982:36(4):680-90.

21. Kim J, Heshka S, Gallagher D, Kotler DP, Mayer L, Albu J, Shen W, Freda PU, Heymsfield SB. Intermuscular adipose tissue-free skeletal muscle mass: estimation by dual-energy X-ray absorptiometry in adults. J Appl Physiol (1985). 2004;97(2):655-60.

22. Kristensen MT, Kehlet $\mathrm{H}$. Most patients regain prefracture basic mobility after hip fracture surgery in a fast-track programme. Dan Med J. 2012;59(6): A4447.

23. Parker MJ, Palmer CR. A new mobility score for predicting mortality after hip fracture. J Bone Joint Surg Br. 1993:75(5):797-8.

24. Magaziner J, Simonsick EM, Kashner TM, Hebel JR, Kenzora JE. Predictors of functional recovery one year following hospital discharge for hip fracture: a prospective study. J Gerontol. 1990;45(3):M101-7.

25. Studenski SA, Peters KW, Alley DE, Cawthon PM, McLean RR, Harris TB, Ferrucci L, Guralnik JM, Fragala MS, Kenny AM, et al. The FNIH sarcopenia project: rationale, study description, conference recommendations, and final estimates. J Gerontol A Biol Sci Med Sci. 2014;69(5):547-58.

26. Harrell Jr FE: rms: Regression Modeling Strategies. R package version 4.0-0. City 2013

27. R Core Team: R: A language and environment for statistical computing. In. Vienna, Austria: R Foundation for Statistical Computing; 2016.

28. Kristensen MT, Foss NB, Kehlet $\mathrm{H}$. Timed up and go and new mobility score as predictors of function six months after hip fracture. Ugeskr Laeger. 2005; 167(35):3297-300.

29. Keene GS, Parker MJ, Pryor GA. Mortality and morbidity after hip-fractures. $\mathrm{Br}$ Med J. 1993;307(6914):1248-50.

30. Parker MJ, Palmer CR. Prediction of rehabilitation after hip fracture. Age Ageing. 1995;24(2):96-8

31. Foss NB, Kristensen MT, Kehlet $\mathrm{H}$. Prediction of postoperative morbidity, mortality and rehabilitation in hip fracture patients: the cumulated ambulation score. Clin Rehabil. 2006:20(8):701-8.

32. Sylliaas H, Brovold T, Wyller TB, Bergland A. Prolonged strength training in older patients after hip fracture: a randomised controlled trial. Age Ageing. 2012;41(2):206-12

33. Handoll HH, Sherrington C, Mak JC. Interventions for improving mobility after hip fracture surgery in adults. Cochrane Database Syst Rev. 2011;3: CD001704.

34. Cesari M, Fielding RA, Pahor M, Goodpaster B, Hellerstein M, van Kan GA, Anker SD, Rutkove S, Vrijbloed JW, Isaac M, et al. Biomarkers of sarcopenia in clinical trials-recommendations from the international working group on sarcopenia. J Cachexia Sarcopenia Muscle. 2012;3(3):181-90.

35. Steihaug OM, Gjesdal CG, Bogen B, Ranhoff AH. Identifying low muscle mass in patients with hip fracture: validation of bioelectrical impedance analysis and anthropometry compared to dual energy X-ray absorptiometry. J Nutr Health Aging. 2016;20(7):685-90.

36. Schaap L, Fox B, Henwood T, Bruyère O, Reginster J-Y, Beaudart C, Buckinx F, Roberts H, Cooper C, Cherubini A. Grip strength measurement: towards a standardized approach in sarcopenia research and practice. Eur Geriatr Med. 2016;7(3):247-55.

37. Beaudart C, McCloskey E, Bruyere O, Cesari M, Rolland Y, Rizzoli R, Araujo de Carvalho I, Amuthavalli Thiyagarajan J, Bautmans I, Bertiere MC, et al. Sarcopenia in daily practice: assessment and management. BMC Geriatr. 2016:16(1):170. 
38. Latham NK, Mehta V, Nguyen AM, Jette AM, Olarsch S, Papanicolaou D, Chandler J. Performance-based or self-report measures of physical function: which should be used in clinical trials of hip fracture patients? Arch Phys Med Rehabil. 2008:89(11):2146-55.

39. Vellas B, Pahor M, Manini T, Rooks D, Guralnik JM, Morley J, Studenski S, Evans W, Asbrand C, Fariello R, et al. Designing pharmaceutical trials for sarcopenia in frail older adults: EU/US task force recommendations. J Nutr Health Aging. 2013;17(7):612-8.

Submit your next manuscript to BioMed Central and we will help you at every step:

- We accept pre-submission inquiries

- Our selector tool helps you to find the most relevant journal

- We provide round the clock customer support

- Convenient online submission

- Thorough peer review

- Inclusion in PubMed and all major indexing services

- Maximum visibility for your research

Submit your manuscript at www.biomedcentral.com/submit 